\title{
Ship Exhaust Gas Plume Cooling
}

\author{
H.M.A. Schleijpen, F.P. Neele \\ TNO Physics and Electronics Laboratory \\ Oude Waalsdorperweg 63, P.O. Box 96864, 2509 JG The Hague, The Netherlands \\ schleijpen@fel.tno.nl
}

\begin{abstract}
The exhaust gas plume is an important and sometimes dominating contributor to the infrared signature of ships. Suppression of the infrared ship signatures has been studied by TNO for the Royal Netherlands Navy over considerable time. This study deals with the suppression effects, which can be achieved using a spray of cold water in the inner parts of the exhaust system. The effects are compared with the effect of cooling with air. A typical frigate size diesel engine serves as an example for gas flow, composition and temperature of the plume. The infrared emission of the cooled an un-cooled exhaust gases is calculated. Both the spectral behaviour and the integrated values over typical bands are discussed. Apart from the signature also some advantages of water exhaust gas cooling for the ship design are discussed.
\end{abstract}

Key words: Infrared signature, Exhaust gas radiation, Signature suppression, Survivability

\section{INTRODUCTION}

Infrared emission from exhaust gas plumes of ships has been a topic of interest since many years. The exhaust plume is an important contributor to the infrared signature of ships. In the 3-5 $\mu \mathrm{m}$ infrared band the plume is often even the dominating contributor. Furthermore, for conventional ship designs, the plume is also close to the highest position of the ship. Therefore, the plume is often the first infrared emission of a ship seen above the horizon by potential threats. Suppression of the infrared plume emission has been studied by TNO for the Royal Netherlands Navy (RNIN) over considerable time. For example studies were done on the effects of plume cooling with ambient air and hull cooling with sea water spray (references 1 and 2 respectively).

This paper reports on a study of infrared plume signature suppression where the effects of air cooling and water cooling are compared. Several companies currently offer systems for exhaust gas cooling using these techniques. For the calculations a frigate size diesel engine serves as example, for typical exhaust gas mass flow, composition and temperature. For the infrared signature analysis we will only focus on the exhaust gases and we will ignore the effects the cooling water or cooling air could have on the metal parts of the stack.

This paper is organised as following: in order to compare the signature reduction effects of air and water cooling, we calculate the plume composition and temperature distribution after the mixing with ambient air or cold water (section 2). For the resulting exhaust gas flows, the suppression effect on the plume signature is estimated (section 3). Finally we will address some design issues (section 4).

\section{COOLING OF EXHAUST GASES}

As a starting point for the calculation of the cooling effect of water or air injection in the hot exhaust plume, we take the ideal case where all the energy is transferred from the hot plume to the ambient air or the sea water spray. The exhaust gas conditions for the diesel engine for three power settings are given in table 1.

In order to calculate the air-cooling effect we assume an ideal mixing process of the exhaust gases with cool ambient air at $20^{\circ} \mathrm{C}$. The final temperature of the cooled gases is calculated taking into account the masses and heat capacities of the hot exhaust gases and the cool air. The effects of unburned particles in hot gases and humidity variations in the cooling air are neglected. Also the possible chemical reactions of oxygen and unburned fuel particles are ignored. The exhaust gas cooling as a function of the flow of cool air is given in figure 1. 
Table 1. Exhaust gas data for the diesel engine

\begin{tabular}{|l|r|r|r|l|}
\hline Power setting & $47 \%$ & $70 \%$ & $100 \%$ & \\
\hline Temp & 314 & 333 & 352 & ${ }^{\circ} \mathrm{C}$ \\
\hline $\mathrm{C}_{\mathrm{p}}$ & 626,9 & 607,3 & 588,8 & $\mathrm{~J} / \mathrm{m}^{3} / \mathrm{K}$ \\
\hline Flow & 7,89 & 11,06 & 14,23 & $\mathrm{~m}^{3} / \mathrm{s}$ \\
\hline Flow & 5.0 & 6.7 & 8.4 & $\mathrm{~kg} / \mathrm{s}$ \\
\hline Composition: & & & & \\
\hline CO2 & 0.0711 & 0.0711 & 0.0711 & $\mathrm{Vol} \%$ \\
\hline H2O & 0.0628 & 0.0628 & 0.0628 & $\mathrm{Vol} \%$ \\
\hline $\mathrm{N} 2$ & 0.6947 & 0.6947 & 0.6947 & $\mathrm{Vol} \%$ \\
\hline $\mathrm{O} 2$ & 0.1737 & 0.1737 & 0.1737 & $\mathrm{Vol} \%$ \\
\hline
\end{tabular}

For the water cooling a spray of small water droplets at $20{ }^{\circ} \mathrm{C}$ is injected in the hot exhaust stream. It is assumed that the water particles evaporate immediately, even before the droplets increase their temperature. In reality, the evaporation in the cooling process will be a more continuous process, where the cooling water heats up and at the same time evaporates at all temperatures between $20^{\circ} \mathrm{C}$ and $100^{\circ} \mathrm{C}$. However, physics requires conservation of energy, and the total energy extracted from the exhaust gas plume will be the same for a given end temperature.

The temperature of the exhaust gases cooled by water evaporation reaches an equilibrium when the mix of exhaust gases and water vapour is fully saturated. Evaporation is then no longer possible and the temperature cannot further decrease by the evaporation of water. For this reason some of the lowest temperatures in figure 2 cannot be reached in practice. Theoretically the exhaust gases can be cooled further by mixing the gases with cold water, without evaporation. However, this process is much less efficient in cooling and requires a much larger water flow.

The equilibrium temperature depends on the gas temperature prior to cooling. For maximum power for this diesel engine we find $55^{\circ} \mathrm{C}$ as equilibrium temperature.

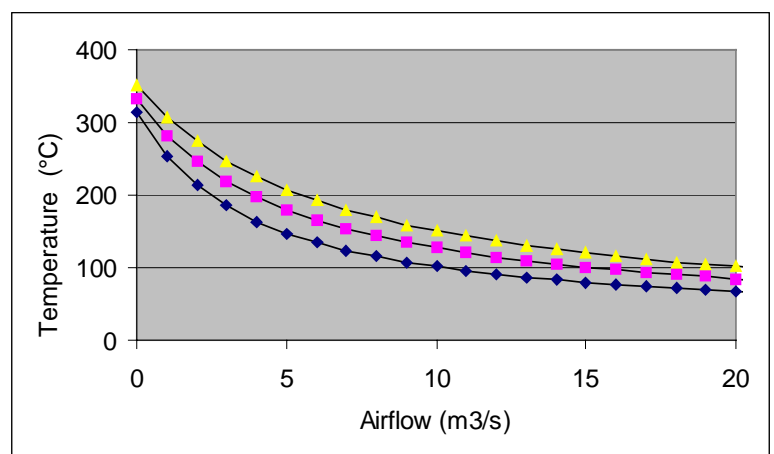

Fig. 1. Cooling of exhaust gases for a frigate diesel engine. Temperature after cooling versus air flow. The curves represent $47 \%, 70 \%$ and $100 \%$ power of the engine (bottom to top).

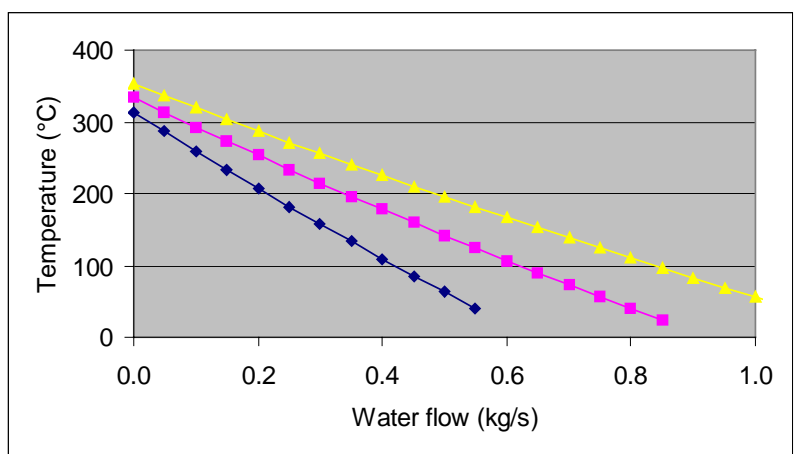

Fig. 2. Cooling of exhaust gases for a frigate diesel engine. Temperature after cooling versus water flow. The curves represent $47 \%, 70 \%$ and $100 \%$ power of the engine (bottom to top).

\section{PLUME SIGNATURE CALCULATIONS}

\subsection{Infrared emission calculations}

The infrared emissions of the various cooled and un-cooled plumes are calculated with NIRATAM. NIRATAM is the NATO Infrared Air Target Model (references 3 and 4). Although this model has been developed for the prediction of aircraft signatures, the code for calculation of infrared plume emissions can also be used for other plumes. 
An essential input for the plume signature calculation is the plume flow field describing the spatial distribution of species concentrations and temperature over the exhaust plume. The flow field is calculated with the NPLUME part of NIRATAM. The inputs for the calculations are the composition, temperature and flow speed of the exhaust gases at the top of the stack. The NPLUME model calculates mixing of coaxial rotationally symmetric gas flows. Due to crosswind and buoyancy effects, the plume of a ship will not be fully rotational symmetric. However, as a first approximation for the hot core of the plume close to the top of the stack, the NPLUME approach is still applicable. A good description of the flow field in the hot core is essential, since the hot core dominates the plume infrared emission.

The infrared emission calculations are done with NIRATAM. Given the approximations in the plume flow field calculations, absolute accuracy in the plume emission predictions is not to be expected. For the purpose of this comparative study, where we wish to estimate the effect of plume cooling compared to un-cooled plumes, relative values are sufficient.

Taking into account that we are most interested in the hot core of the plume and the immediate background, the field of view for the emission calculations is taken as a square of $10 \mathrm{~m} \times 10 \mathrm{~m}$ just above the stack. All plume spectra shown below will give the contrast spectrum of the plume with the background sky close to the horizon. For estimates of cooling effects on the total intensity of exhaust plumes, the results of this study should be scaled proportionally to measured data of exhaust plume infrared emissions.

Infrared emission spectra are calculated for the wavenumber range from $750 \mathrm{~cm}^{-1}$ to $4750 \mathrm{~cm}^{-1}$, corresponding to the wavelength range from $2.1 \mu \mathrm{m}$ to $13.3 \mu \mathrm{m}$. The emissions are calculated as "seen" from a range of $100 \mathrm{~m}$. For longer ranges it is necessary to correct for the atmospheric transmission as a function of wavelength. Especially in the spectral bands where the gases $\mathrm{H}_{2} \mathrm{O}$ and $\mathrm{CO}_{2}$ in the exhaust plume emit, the $\mathrm{H}_{2} \mathrm{O}$ and $\mathrm{CO}_{2}$ in the atmosphere cause the strongest absorption. Therefore, one has to bear in mind that in general the effect of plume cooling on the observed signature increases with range.

\subsection{Spectral features in Exhaust Gas plumes}

As a baseline the spectra for the un-cooled diesel exhaust plume without pollution are calculated. Figure 3 shows the apparent spectral radiant intensity contrast spectrum over the full spectral range as seen at $100 \mathrm{~m}$. This figure visualises the typical spectral emission of a plume. Below $800 \mathrm{~cm}^{-1}$ a $\mathrm{CO}_{2}$ band emission is observed. These features appear above $12.5 \mu \mathrm{m}$. Between $1150 \mathrm{~cm}^{-1}$ and $2150 \mathrm{~cm}^{-1}(4.6-8.7 \mu \mathrm{m})$ a water band emission is located. Between $2200 \mathrm{~cm}^{-1}$ and $2400 \mathrm{~cm}^{-1}(4.1-4.5 \mu \mathrm{m})$ is the $\mathrm{CO}_{2}$ emission with the so-called blue spike (near $\left.2400 \mathrm{~cm}^{-1}, 4.1 \mu \mathrm{m}\right)$ and the red wing (near $\left.2200 \mathrm{~cm}^{-1}, 4.5 \mu \mathrm{m}\right)$ is visible. From $3000 \mathrm{~cm}^{-1}$ to $4000 \mathrm{~cm}^{-1}(2.5-3.3 \mu \mathrm{m})$, again a water band is found. A CO band is to be found around $2150 \mathrm{~cm}^{-1}(4.6 \mu \mathrm{m})$. CO is not included in the standard plume flow field calculations, and will be discussed under the polluted plumes. In the further analysis we focus on the atmospheric windows 2 to $5 \mu \mathrm{m}$ (2000$\left.5000 \mathrm{~cm}^{-1}\right)$ and 8 to $12 \mu \mathrm{m}\left(833-1250 \mathrm{~cm}^{-1}\right)$, and the features in these bands. Therefore, the $\mathrm{CO}_{2}$ features above $12.5 \mu \mathrm{m}$ will not be discussed below.

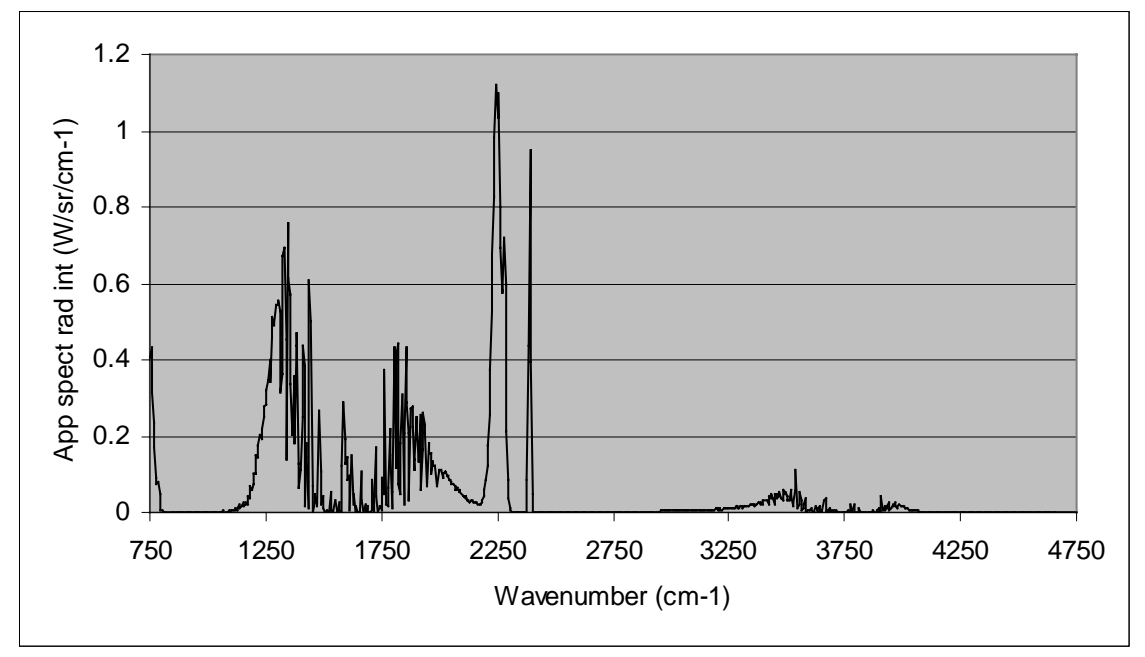

Fig. 3. Apparent spectral radiant intensity contrast for an un-cooled diesel plume as seen at $100 \mathrm{~m}$. 


\subsection{Range effects}

Figures 4 to 5 show the effect of atmospheric absorption on the spectra for ranges of $100 \mathrm{~m}, 250 \mathrm{~m}, 500 \mathrm{~m}, 1000 \mathrm{~m}$, $2500 \mathrm{~m}$ and $5000 \mathrm{~m}$ (top to bottom). In these apparent radiant intensity graphs, the $1 / \mathrm{R}^{2}$ range effect is not taken into account.

In the 8 to $12 \mu \mathrm{m}$ band (figure 4) we see that the only relevant contribution to the plume is in the range between 1150 and $1250 \mathrm{~cm}^{-1}$. The atmospheric absorption in this band shows the effect of a gradual decrease of intensity.

In the 2 to $5 \mu \mathrm{m}\left(2000-5000 \mathrm{~cm}^{-1}\right)$ band we focus on the $\mathrm{CO}_{2}$ features. The $\mathrm{CO}_{2}$ features (figure 5) show a complex behaviour. The curves do not only show a drop in intensity, but also show that the remaining emission through the atmosphere concentrates near the outer sections of the band. This is due to the fact that the $\mathrm{CO}_{2}$ absorption band in the cool atmosphere increases in width with increasing range.

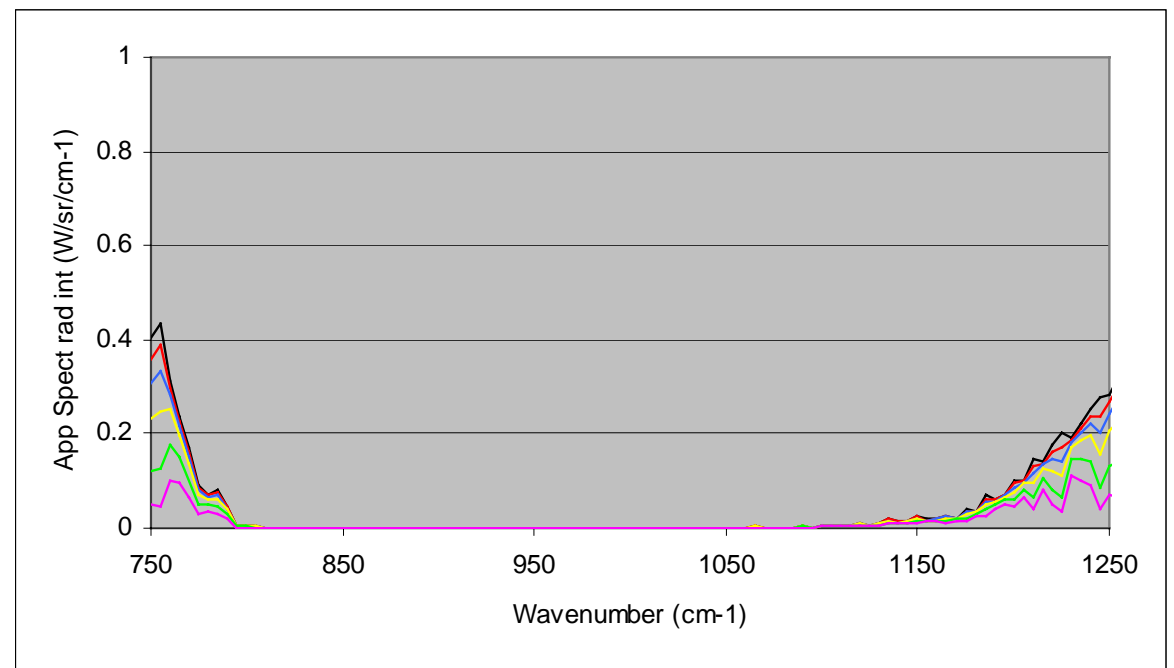

Fig. 4. Features in the 8 to $12 \mu \mathrm{m}$ band. The effect of the atmospheric absorption for ranges of $100 \mathrm{~m}, 250 \mathrm{~m}, 500 \mathrm{~m}, 1000 \mathrm{~m}, 2500$ $\mathrm{m}$ and $5000 \mathrm{~m}$ (top to bottom).

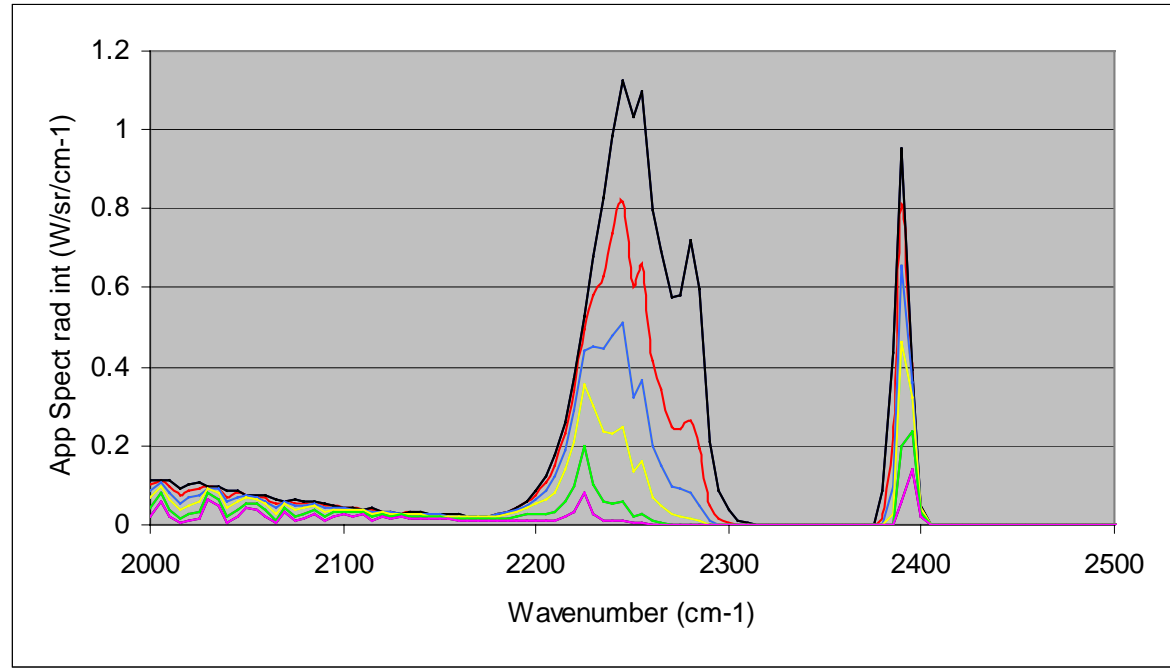

Fig. 5. $\mathrm{CO}_{2}$ features in the 2 to $5 \mu \mathrm{m}$ band. The effect of the atmospheric absorption for ranges of $100 \mathrm{~m}, 250 \mathrm{~m}, 500 \mathrm{~m}, 1000 \mathrm{~m}$, $2500 \mathrm{~m}$ and $5000 \mathrm{~m}$ (top to bottom). 


\subsection{Water Cooling effects}

The results of water cooling on the various features in the two bands are shown in figures 6 through 8 . All curves are calculated for a stand-off range of $100 \mathrm{~m}$. Note that for the $50^{\circ} \mathrm{C}$ case, the water content in the cooled plume mix is above the saturation threshold. The results for $50^{\circ} \mathrm{C}$ are therefore given as an indication only.

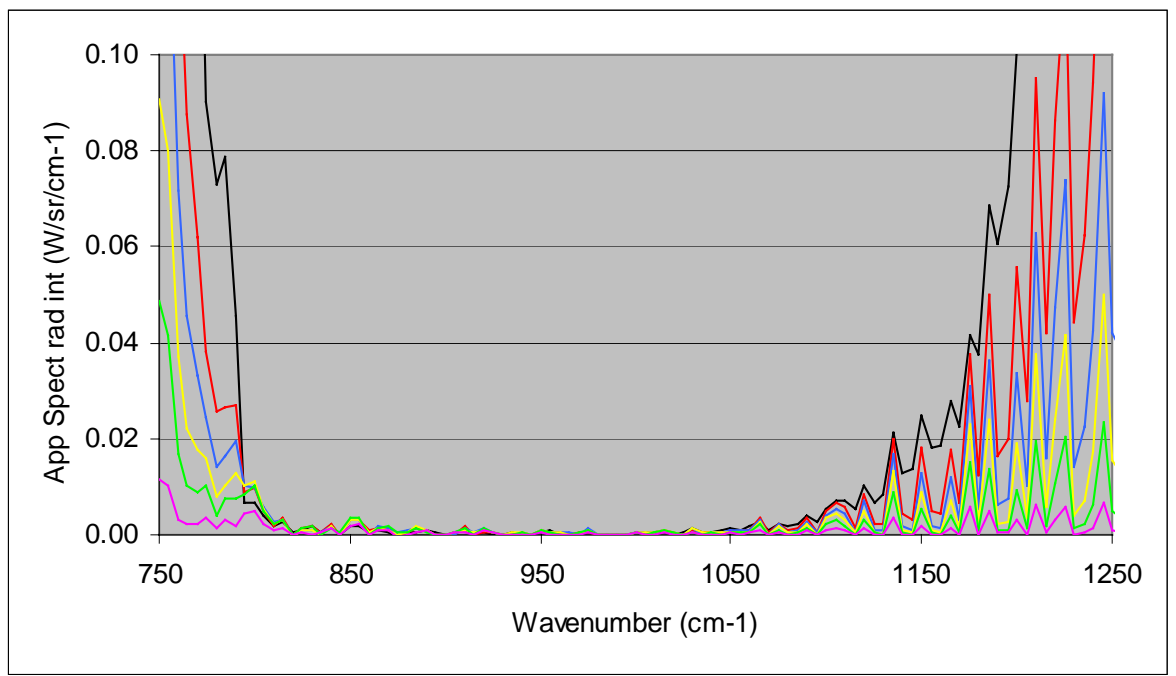

Fig. 6. Features in the 8 to $12 \mu \mathrm{m}$ band. The effect of water-cooling for plumes: Un-cooled, $250{ }^{\circ} \mathrm{C}, 200{ }^{\circ} \mathrm{C}, 150{ }^{\circ} \mathrm{C}, 100{ }^{\circ} \mathrm{C}, 50{ }^{\circ} \mathrm{C}$ top to bottom.

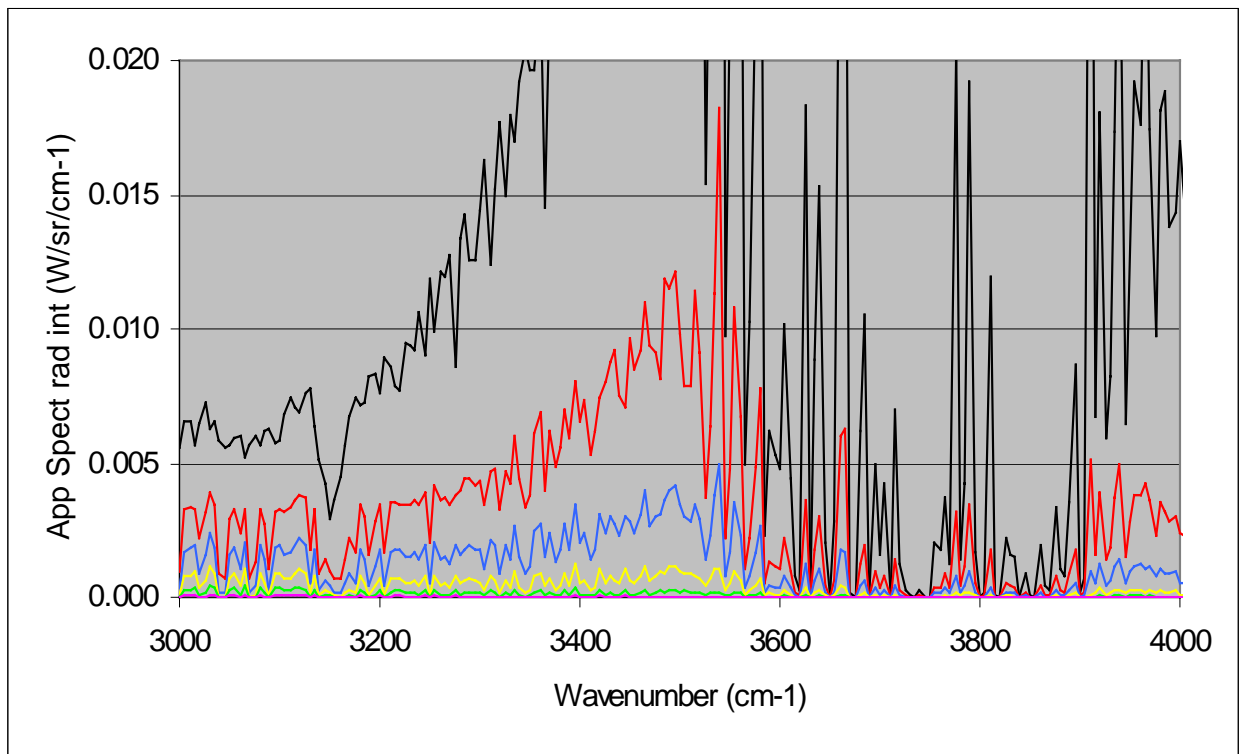

Fig. 7. Water features in the 2 to $5 \mu \mathrm{m}$ band. The effect of water-cooling for plumes: un-cooled, $250{ }^{\circ} \mathrm{C}, 200{ }^{\circ} \mathrm{C}, 150{ }^{\circ} \mathrm{C}, 100{ }^{\circ} \mathrm{C}, 50$ ${ }^{\circ} \mathrm{C}$ top to bottom. 


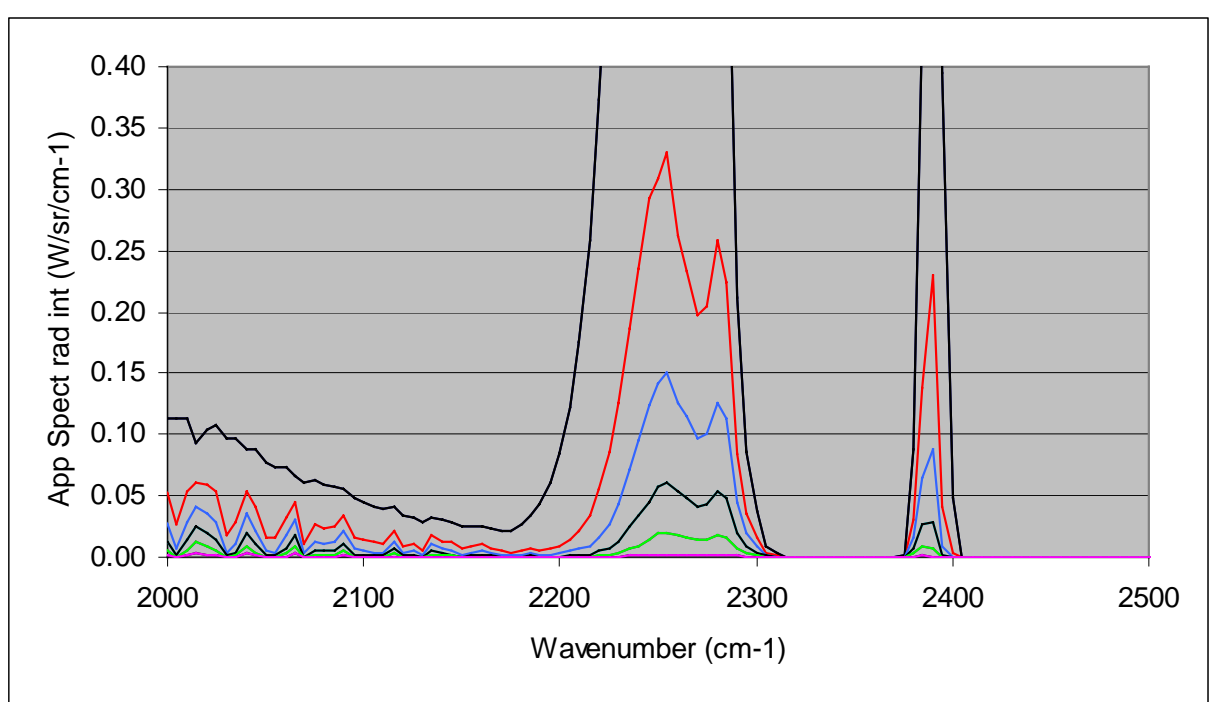

Figure $8 . \mathrm{CO}_{2}$ features in the 2 to $5 \mu \mathrm{m}$ band. The effect of water-cooling for plumes: un-cooled, $250{ }^{\circ} \mathrm{C}, 200{ }^{\circ} \mathrm{C}, 150{ }^{\circ} \mathrm{C}, 100{ }^{\circ} \mathrm{C}, 50$ ${ }^{\circ} \mathrm{C}$ (top to bottom).

\subsection{Comparison water and air cooling}

Apart from some details, which will be discussed below, air cooling gives the same results as the results shown for water cooling in figures 6 through 8. To enable a numerical analysis the spectral output is integrated over the full spectral bands (2-5 $\mu \mathrm{m}$ and 8-12 $\mu \mathrm{m})$ and over sections of the bands with and without spectral features. The results are compared in table 2 below.

Table 2 Integrated emission (radiant intensity in W/sr) for cooled and un-cooled diesel plumes over the full spectral band and selected band sections.

\begin{tabular}{|l|l|l|r|r|r|r|r|r|r|}
\hline & & Temp & Uncooled & \multicolumn{1}{c}{$200^{\circ} \mathrm{C}$} & $200^{\circ} \mathrm{C}$ & $150^{\circ} \mathrm{C}$ & $150{ }^{\circ} \mathrm{C}$ & $100{ }^{\circ} \mathrm{C}$ & $100^{\circ} \mathrm{C}$ \\
\hline & $\mu \mathrm{m}$ & $\mathrm{cm}^{-1}$ & & Water & Air & Water & Air & Water & Air \\
\hline $8-12 \mu \mathrm{m}$ & & & & & & & & & \\
\hline Full band & $8.0-12.0$ & $835-1250$ & 11.704 & 3.082 & 2.120 & 1.734 & 1.282 & 0.938 & 0.880 \\
\hline "Clean" & $8.7-12.0$ & $835-1150$ & 0.684 & 0.418 & 0.290 & 0.325 & 0.241 & 0.255 & 0.242 \\
\hline $\mathrm{H}_{2} \mathrm{O}$ & $8.0-8.7$ & $1150-1250$ & 11.020 & 2.664 & 1.830 & 1.409 & 1.041 & 0.683 & 0.638 \\
\hline $2-5 \mu \mathrm{m}$ & & & & & & & & & \\
\hline Full band & $2.1-5.0$ & $2000-4750$ & 94.630 & 11.796 & 14.048 & 4.734 & 6.454 & 1.619 & 2.587 \\
\hline "Clean" & $2.1-2.5$ & $4000-4750$ & 0.706 & 0.037 & 0.026 & 0.008 & 0.007 & 0.001 & 0.002 \\
\hline $\mathrm{H}_{2} \mathrm{O}$ & $2.5-3.3$ & $3000-4000$ & 14.219 & 1.250 & 0.982 & 0.393 & 0.340 & 0.103 & 0.113 \\
\hline "Clean" & $3.3-4.0$ & $2500-3000$ & 0.532 & 0.094 & 0.063 & 0.038 & 0.028 & 0.013 & 0.012 \\
\hline $\mathrm{CO}_{2}$ & $4.0-4.6$ & $2170-2500$ & 68.654 & 8.203 & 11.392 & 3.239 & 5.252 & 1.056 & 2.016 \\
\hline $\mathrm{H}_{2} \mathrm{O}$ & $4.6-5.0$ & $2000-2170$ & 10.518 & 2.212 & 1.585 & 1.056 & 0.828 & 0.446 & 0.445 \\
\hline
\end{tabular}

Table 2 shows that the emission for corresponding temperatures is slightly higher for the water-cooled plume in the 8-12 $\mu \mathrm{m}$ band. This is due to the fact that this feature is a water emission, which is slightly higher in intensity due to the higher percentage of water in the water cooled plume. The same effect is visible for the water features in the $2-5 \mu \mathrm{m}$ band. The reverse effect is visible for the $\mathrm{CO}_{2}$ features in the $2-5 \mu \mathrm{m}$ band. The $\mathrm{CO}_{2}$ feature also shows the effect of cooling the gases in the exhaust plume. Compared to the un-cooled plume, the emission is spread over a spectral region closer to the centre of the band. In this case the atmospheric absorption will be even more efficient in reducing the transmitted emission of the gases, since the absorption is most effective in the centre of the emission bands.

As expected, there is only a significant emission in the "gas bands". This is because we compared the ideal case of a "clean" plume with gases only. At comparable temperatures there is no clear preference for one of the two cooling mechanisms from the point of view of signature reduction. 


\subsection{Polluted plumes: Carbon Particles and CO}

Apart from the exhaust gases also unburned fuel is found in real diesel plumes. The diesel engine manufacturer gives a nominal amount of $6.810^{-8} \mathrm{~g} / \mathrm{cm}^{3}$, of soot in the plume. The soot will behave as a black body and causes a continuum spectrum in the emission. Figure 9 shows the calculated emission for several soot levels: 0, 0.1, and 1 times the level given by the manufacturer. The continuum contribution to the spectrum is now clearly visible in the ranges, which were indicated as "clean" in the unpolluted plumes.

Figure 10 gives the same results for a water-cooled plume at a temperature of $100{ }^{\circ} \mathrm{C}$. Note the difference in scale in the spectral plot. As can be seen, the emission in the 8-12 $\mu \mathrm{m}$ band for a cooled plume with a considerable amount of carbon particles at $100{ }^{\circ} \mathrm{C}$ can become comparable to the output of an un-cooled plume with a very low amount of particles. Tables 3 and 4 compare the results. A relatively high soot content in the cooled plume $\left(6.810^{-7} \mathrm{~g} / \mathrm{cm}^{3}\right)$ causes an emission level in the same order as the un-cooled plume in the 8-12 $\mu \mathrm{m}$ band. In the 3-5 $\mu \mathrm{m}$ the cooled polluted plume is still much lower in emission than the un-cooled plume.

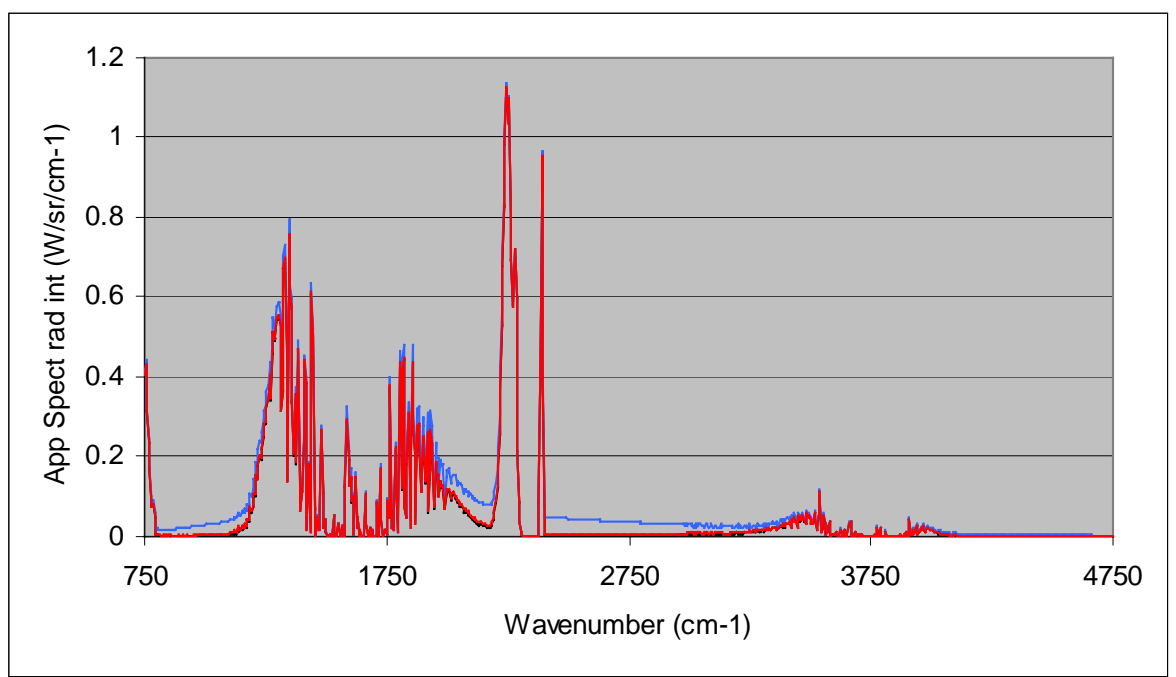

Fig. 9. Apparent spectral radiant intensity contrast for an un-cooled diesel plume as seen at $100 \mathrm{~m}$ with $0,0.1$ and 1 times $6.810^{-8}$ $\mathrm{g} / \mathrm{cm}^{3}$ of soot in the plume (bottom to top).

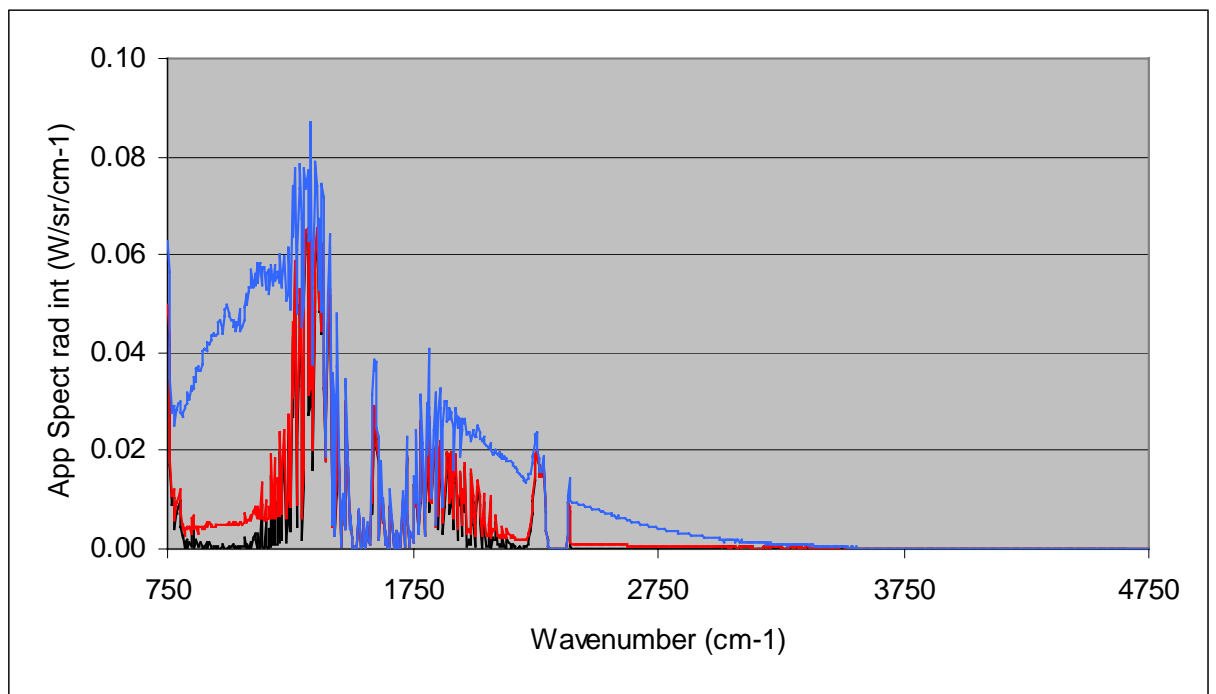

Fig. 10. Apparent spectral radiant intensity contrast for a water-cooled diesel plume as seen at $100 \mathrm{~m}$ with 0,1 and 10 times $6.810^{-8}$ $\mathrm{g} / \mathrm{cm}^{3}$ of soot in the plume (bottom to top). 
Table 3 Integrated emission (radiant intensity in W/sr) for diesel plumes with different amounts of unburned fuel. Integrated over the full spectral band and selected band sections

\begin{tabular}{|l|l|l|r|r|r|r|}
\hline & & Soot $\mathrm{g} / \mathrm{cm}^{3}$ & 0 & $6,810^{-9}$ & $6,810^{-8}$ & $6,810^{-7}$ \\
\hline & $\mu \mathrm{m}$ & $\mathrm{cm}^{-1}$ & & & & \\
\hline $8-12 \mu \mathrm{m}$ & & & & & & \\
\hline Full band & $8.0-12.0$ & $835-1250$ & 11.7 & 13.0 & 24.6 & 136.7 \\
\hline & $8.7-12.0$ & $835-1150$ & 0.7 & 1.6 & 9.4 & 86.0 \\
\hline $\mathrm{H}_{2} \mathrm{O}$ & $8.0-8.7$ & $1150-1250$ & 11.0 & 11.4 & 15.1 & 50.6 \\
\hline $3-5 \mu \mathrm{m}$ & & & & & & \\
\hline Full band & $2.1-5.0$ & $2000-4750$ & 94.6 & 99.4 & 141.2 & 501.7 \\
\hline & $2.1-2.5$ & $4000-4750$ & 0.7 & 1.0 & 3.8 & 26.4 \\
\hline $\mathrm{H}_{2} \mathrm{O}$ & $2.5-3.3$ & $3000-4000$ & 14.2 & 15.1 & 22.4 & 84.3 \\
\hline & $3.3-4.0$ & $2500-3000$ & 0.5 & 2.3 & 18.2 & 154.5 \\
\hline $\mathrm{CO}_{2}$ & $4.0-4.6$ & $2170-2500$ & 68.7 & 69.5 & 77.1 & 143.9 \\
\hline $\mathrm{H}_{2} \mathrm{O}$ & $4.6-5.0$ & $2000-2170$ & 10.5 & 11.4 & 19.6 & 92.6 \\
\hline
\end{tabular}

Table 4 Integrated emission (radiant intensity in W/sr) for water cooled diesel plumes $\left(100{ }^{\circ} \mathrm{C}\right)$ with different amounts of unburn fuel. Integrated over the full spectral band and selected band sections.

\begin{tabular}{|l|l|l|r|r|r|}
\hline & & Soot $\mathrm{g} / \mathrm{cm}^{3}$ & 0 & $6,810^{-8}$ & $6,810^{-7}$ \\
\hline & $\mu \mathrm{m}$ & $\mathrm{cm}^{-1}$ & & & \\
\hline $8-12 \mu \mathrm{m}$ & & & & & \\
\hline Full band & $8.0-12.0$ & $835-1250$ & 0.94 & 2.88 & 19.89 \\
\hline & $8.7-12.0$ & $835-1150$ & 0.26 & 1.70 & 14.35 \\
\hline $\mathrm{H}_{2} \mathrm{O}$ & $8.0-8.7$ & $1150-1250$ & 0.68 & 1.18 & 5.54 \\
\hline $3-5 \mu \mathrm{m}$ & & & & & \\
\hline Full band & $2.1-5.0$ & $2000-4750$ & 1.62 & 2.48 & 9.42 \\
\hline & $2.1-2.5$ & $4000-4750$ & 0.00 & 0.01 & 0.03 \\
\hline $\mathrm{H}_{2} \mathrm{O}$ & $2.5-3.3$ & $3000-4000$ & 0.10 & 0.15 & 0.55 \\
\hline & $3.3-4.0$ & $2500-3000$ & 0.01 & 0.26 & 2.26 \\
\hline $\mathrm{CO}_{2}$ & $4.0-4.6$ & $2170-2500$ & 1.06 & 1.29 & 3.16 \\
\hline $\mathrm{H}_{2} \mathrm{O}$ & $4.6-5.0$ & $2000-2170$ & 0.45 & 0.77 & 3.43 \\
\hline
\end{tabular}

Carbon monoxide emission is not included in the standard calculations. The amount of CO in the plume is very limited under normal "clean" operation of the engines. Typical values are around $0.1 \mathrm{vol} \%$ for the diesel engine. Inefficient combustion leads to more $\mathrm{CO}$ in the plume. For the calculations we have taken 0.2 and 1 vol \% for polluted plumes. Although the $\mathrm{CO}$ emission is in general small compared to the $\mathrm{CO}_{2}$ emission, it can be significant at longer ranges since the atmospheric transmission in the $\mathrm{CO}$ emission band is much better than in the $\mathrm{CO}_{2}$ band.

The effect of $\mathrm{CO}$ in the plume emission is visible only in the spectral range 2000-2250 $\mathrm{cm}^{-1}$ (Figure 11). There is no effect in the 8-12 $\mu \mathrm{m}$ band. Plume cooling reduces also the $\mathrm{CO}$ emission albeit less prominently than the $\mathrm{CO}_{2}$ emission. 


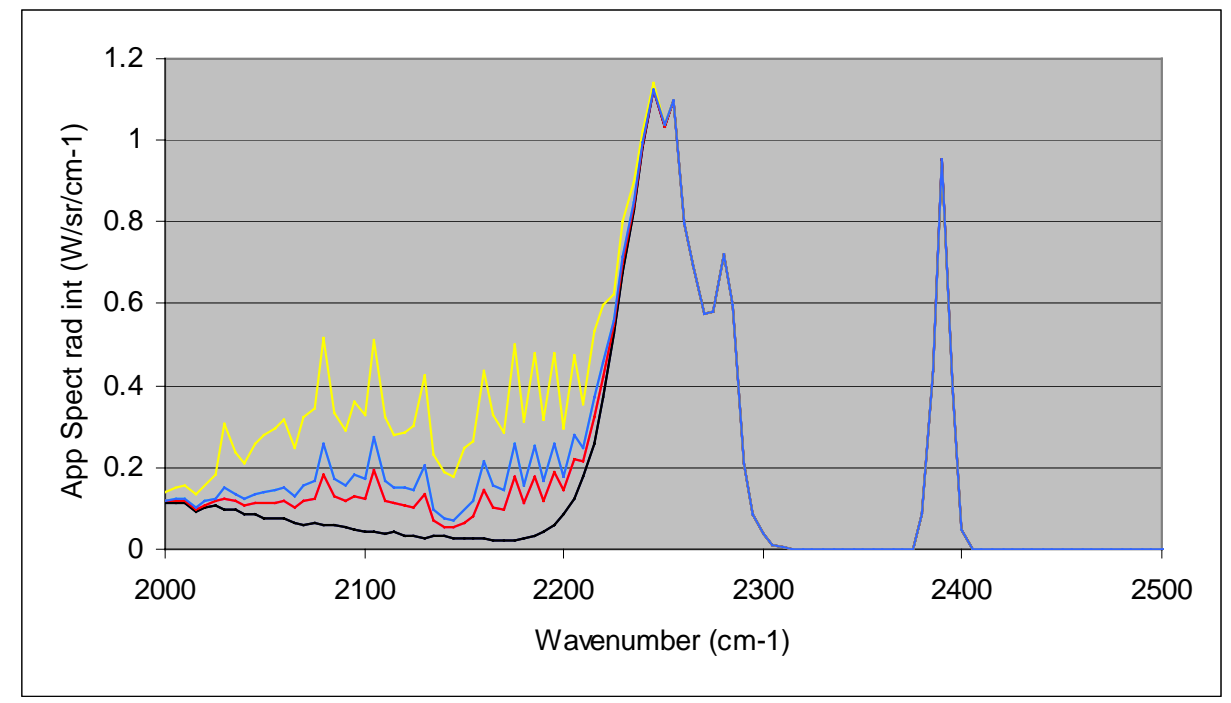

Fig. 11.CO features in the 4 to $5 \mu \mathrm{m}$ band in an un-cooled diesel plume. The effect of $0 \%, 0.1 \% 0.2 \%$ and $1.0 \%$ of $\mathrm{CO}$ in the plume (bottom to top).

\subsection{Residual water in the plume}

In a non-ideal case of water cooling some residual water droplets will be found in the plume, causing particle blackbody emission. We will try to get a rough estimate of the increase in infrared emission due to the presence of water droplets in the plume. Since NIRATAM can only calculate the black-body emission of carbon particles, we treat the water droplets as carbon particles and ignore the difference in particle size distribution and the difference in emissivity. An amount of $0.82 \mathrm{~kg} / \mathrm{s}$ of water is needed to cool the full power diesel exhaust gases down to $100{ }^{\circ} \mathrm{C}$. If $1 \%$ of the water remains liquid this is approximately $8 \mathrm{~g} / \mathrm{s}$ on a exhaust gas flow of $9.82 \mathrm{~m}^{3} / \mathrm{s}$. This equals roughly $0.8 \mathrm{~g} / \mathrm{m}^{3}$, which is about 10 times the nominal level of soot in the plume. The results for $0.1 \%, 1.0 \%$ and $10 \%$ of non-evaporated water are given in figure 12 and table 5.

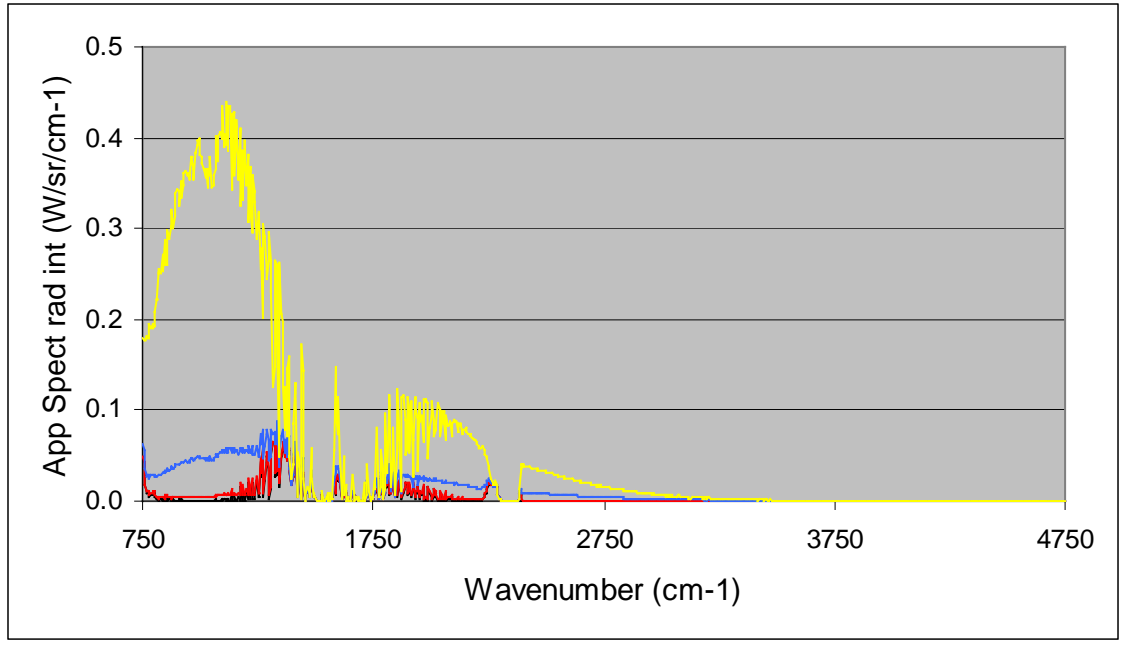

Fig. 12: Apparent spectral radiant intensity contrast for a water-cooled diesel plume $\left(100{ }^{\circ} \mathrm{C}\right)$ as seen at $100 \mathrm{~m}$ with $0 \%, 0.1 \% 1 \%$ and $10 \%$ of non-evaporated water in the plume (bottom to top). 
Table 5 Integrated emission (radiant intensity in W/sr) for water cooled diesel plumes $\left(100{ }^{\circ} \mathrm{C}\right)$ with $0.1 \%, 1.0 \%$ and $10 \%$ of non-evaporated water.

\begin{tabular}{|l|l|l|r|r|r|r|}
\hline & & Residual water & \multicolumn{1}{l}{$0 \%$} & \multicolumn{1}{l}{$0.1 \%$} & $1.0 \%$ & \multicolumn{1}{l|}{$10 \%$} \\
\hline $8-12 \mu \mathrm{m}$ & $\mu \mathrm{m}$ & $\mathrm{cm}^{-1}$ & & & & \\
\hline Full band & $8.0-12.0$ & $835-1250$ & 0.94 & 2.88 & 19.89 & 148.71 \\
\hline & $8.7-12.0$ & $835-1150$ & 0.26 & 1.70 & 14.35 & 113.11 \\
\hline $\mathrm{H}_{2} \mathrm{O}$ & $8.0-8.7$ & $1150-1250$ & 0.68 & 1.18 & 5.54 & 35.60 \\
\hline $3-5 \mu \mathrm{m}$ & & & & & & \\
\hline Full band & $2.1-5.0$ & $2000-4750$ & 1.62 & 2.48 & 9.42 & 34.62 \\
\hline & $2.1-2.5$ & $4000-4750$ & 0.00 & 0.01 & 0.03 & 0.09 \\
\hline $\mathrm{H}_{2} \mathrm{O}$ & $2.5-3.3$ & $3000-4000$ & 0.10 & 0.15 & 0.55 & 1.57 \\
\hline & $3.3-4.0$ & $2500-3000$ & 0.01 & 0.26 & 2.26 & 8.61 \\
\hline $\mathrm{CO}_{2}$ & $4.0-4.6$ & $2170-2500$ & 1.06 & 1.29 & 3.16 & 9.97 \\
\hline $\mathrm{H}_{2} \mathrm{O}$ & $4.6-5.0$ & $2000-2170$ & 0.45 & 0.77 & 3.43 & 14.39 \\
\hline
\end{tabular}

Compared to the un-cooled plume, even with $10 \%$ residual water in the plume the infrared emission is still less than the un-cooled plume in the 2-5 $\mu \mathrm{m}$ band. Within this band the situation in the "clean" bands (2.1-2.5 $\mu \mathrm{m}$ and 3.3-4.0 $\mu \mathrm{m})$ becomes slightly worse. The situation for $1 \%$ residual water is still better than the un-cooled plume with the nominal soot level. For the $8-12 \mu \mathrm{m}$ band the situation is different. In this band the emission of a plume with $1 \%$ residual water, is already comparable to an un-cooled plume with a limited amount of soot.

Although the situation in the $8-12 \mu \mathrm{m}$ band seems a problem, one has to bear in mind that in this band the plume accounts typically for $5 \%$ of the total signature at maximum. For a solar heated ship this percentage drops considerably for the 8-12 $\mu \mathrm{m}$ band. For the 2-5 $\mu \mathrm{m}$ band, the plume contribution is more important and often even dominating.

The results presented here for residual water droplets in the plume are given for plume temperatures of $100{ }^{\circ} \mathrm{C}$. The effects of residual water will be stronger for higher plume temperatures. On the other hand the risk of residual water is smaller in these cases, since less water is needed to cool the plume and also because the temperature of the exhaust gas mixture is not close to the saturation temperature. The effects of residual water show that the design of a water cooling system must minimise the residual water in the plume.

Cooling of exhaust gases has a number of operational advantages. The susceptibility of the ship for IR-guided threats is reduced significantly, as gas cooling removes the traditional hot spot of exhaust plume.

Signature suppression is not a goal in itself; it must contribute to the survivability of a military platform. A possible figure of merit is the calculation of lock-on or detection ranges for certain threats (reference 1) or the lock on behaviour in the presence of decoys (reference 5).

\section{GENERAL OBSERVATIONS}

The signature effects of water and air cooling of exhaust gases are discussed in the previous section. Application of these cooling techniques has implications for the ship design.

\subsection{Water Cooling}

- Water cooling reduces the volume of exhaust gases. This results in a smaller exhaust pipe system and therefore less weight per meter exhaust pipe, while maintaining the same flow speed of the exhaust gases. Smaller pipes will also allow re-routing of the exhaust gases towards the rear of the ship instead of the conventional stack design. Due to the lower exhaust temperature less heat will be dissipated in the ship. Both reduced weight of the stack and the possibility of re-routing of exhaust gases will bring the centre of gravity lower in the ship, allowing more weight for sensors in the top of the mast.

- Water cooling requires the use of seawater. This will create a highly corrosive environment. The proper choice of materials can reduce this problem. 
- The water spray will require an active system, which will need maintenance and power. If the exhaust design has the proper dimensions, one can decide to build a system in which the cooling can be switched off in the absence of threats. The dimensions must be such that the volume of the un-cooled exhaust gases can be handled.

\subsection{Air cooling}

- Air cooling increases the volume of exhaust gases. This will result in a bigger exhaust system with more weight. For this reason air-cooling seems less suitable for non-conventional exhaust designs. A conventional stack with cooling devices installed will add extra weight in the topside of the ship.

- Air cooling can be done either actively using fans, or passively using a diffusor. The latter option does not require maintenance or power, but will not yield temperatures much lower than $200{ }^{\circ} \mathrm{C}$ (reference 6).

\section{CONCLUSIONS}

The results of the calculations show that both air-cooling and water cooling of the exhaust gases of ships can contribute significantly to signature reduction. Specific conditions for cooling have been discussed.

Apart from the signature reduction itself, water cooling allows flexibility in ship design, such as exhausts near the water surface, which have additional benefit from the signature point of view.

\section{ACKNOWLEDGEMENT}

The financial support of the Royal Netherlands Navy is gratefully acknowledged.

\section{REFERENCES}

1. H.M.A. Schleijpen, "Evaluation of infrared signature suppression of ships", in Targets and Backgrounds: Characterization and Representation II, W.R. Watkins, and D. Clement, editors, Proc. SPIE Vol. 2742, pages 245254, Orlando (FL), USA, Apr. 1996.

2. F.P. Neele, and W. de Jong, "Prewetting systems as an IR signature control tool", Targets and Backgrounds VIII: Characterization and Representation, W.R. Watkins, D. Clement, and W.R. Reynolds, editors, Proc. SPIE Vol. 4718, pages 156-163, Orlando (FL), USA, Apr. 2002.

3. K. Beier, SPIE Vol 972 on Infrared Technolgy, 1988, p363.

4. M. Fair, NATO IR Air Target Signature Prediction Model (NIRATAM), $2^{\text {nd }}$ NATO IRIS Joint Symposium June 1996.

5. W. de Jong, S.P. van den Broek, and R. van der Nol, IR seeker simulator to evaluate IR decoy effectiveness Targets and Backgrounds VIII: Characterization and Representation, W.R. Watkins, D. Clement, and W.R. Reynolds, editors, Proc. SPIE Vol. 4718, pages 164-172, Orlando (FL), USA, Apr. 2002.

6. J. Thompson, D. Vaitekunas, B. Brooking, presented at SMI Pursuit of Stealth Feb 2000. 